\title{
Florid cemento-osseous dysplasia and peripheral giant cell granuloma in a patient with neurofibromatosis $1^{*}$
}

\author{
Dmitry José de Santana Sarmento ${ }^{1}$ \\ José Cadmo Wanderley Peregrino de Araújo Filho ${ }^{3}$ \\ Éricka Janine Dantas da Silveira ${ }^{5}$
}

\author{
Sérgio Henrique Gonçalves de Carvalho \\ Marianne de Vasconcelos Carvalho ${ }^{4}$
}

DOI: http:/ /dx.doi.org/10.1590/abd1806-4841.20175277

\begin{abstract}
We report a 35-year-old mulatto female patient with neurofibromatosis Type 1 who presented with facial asymmetry. The patient had two lesions: florid cemento-osseous dysplasia associated with peripheral giant cell granuloma. She was referred for surgical treatment of the peripheral giant cell granuloma and the florid cemento-osseous dysplasia was treated conservatively by a multidisciplinary team. So far, no changes have been observed in the patient's clinical status. We observed no recurrence of peripheral giant cell granuloma. To the best of our knowledge, the present case is the first report of a patient with neurofibromatosis Type 1 associated with a giant cell lesion and florid cemento-osseous dysplasia.
\end{abstract}

Keywords: Dermatology; Granuloma, Giant Cell; Neurofibromatosis 1

\section{INTRODUCTION}

Neurofibromatosis Type 1 (NF-1), formerly known as von Recklinghausen neurofibromatosis, is an autosomal dominantly inherited genetic disorder caused by a spectrum of mutations affecting the neurofibromatosis 1 gene. Osseous dysplasias are idiopathic processes located in the periapical region of the tooth-bearing jaw areas characterized by a replacement of normal bone by fibrous tissue and metaplastic bone. Peripheral giant cell granuloma (PGCG) is the most common oral giant cell lesion. It normally presents as a soft tissue purplish-red nodule consisting of multinucleated giant cells in a background of mononuclear stromal cells and extravasated red blood cells. ${ }^{1-10}$ We report a 35 -year-old mulatto female patient with neurofibromatosis Type 1 who presented with facial asymmetry and had florid cemento-osseous dysplasia and PGCG.

\section{CASE REPORT}

A 35-year-old mulatto female patient came to our clinic with a complaint of facial asymmetry. We observed a single diffuse swelling on the left side of her face in the anterior mandibular region, with 6 months of evolution. We also observed peripheral cutaneous neurofibromas, mainly on the trunk and limbs, café-au-lait spots, a lot of small brownish axillary freckling, and a glioma on the left optic nerve (Figure 1). The patient reported a paternal family history of NF-1. The patient fulfilled the diagnostic criteria for NF-1. In- traoral examination revealed a painless extra-osseous purplish-red nodule of soft consistency. Bleeding and areas of necrosis were also observed. The nodule was located in the premolar region and had $4 \mathrm{~cm}$ in its greatest diameter (Figure 1). Incisional biopsy and histopathological examination confirmed the diagnosis of PGCG, showing a highly cellular stroma of connective tissue consisting of a proliferation of spindle-shaped fibroblasts, multiple multinucleated giant cells, extravasated red blood cells, and trabeculae of reactive bone (Figure 2). A panoramic x-ray and CT scanning revealed a large mixed lesion, predominantly radiodense, occurring in two jaw quadrants. The images were compatible with florid cemento-osseous dysplasia (Figure 3). A multidisciplinary team including a dermatologist, an ophthalmologist, a geneticist, and a maxillofacial surgeon followed the patient. At that moment, no changes were observed in clinical status. The PGCG showed no recurrence.

\section{DISCUSSION}

NF-1 is a genetic disorder caused by an autosomal dominant inheritance, characterized by high penetrance and variable expressivity. The genetic amendments are represented by deletions, insertions, or mutations of the gene associated with NF-1. This is a tumor suppressor gene. ${ }^{1-3}$ NF-1 is characterized by the presence of café-au-lait macules, peripheral neurofibromas, Lisch nodules, axillary freckling,

\section{Received on 22.10.2015}

Approved by the Advisory Board and accepted for publication on 26.01.2016

Work performed at Universidade Estadual da Paraíba (UEPB) - Araruna (PB), Brazil.

Financial support: none.

Conflict of interest: none.

\footnotetext{
Department of Oral Pathology, Universidade de São Paulo (USP) - São Paulo (SP), Brazil.

Department of Odontology, Universidade Estadual da Paraíba (UEPB) - Araruna (PB), Brazil.

Department of Odontology, Universidade Federal de Campina Grande (UFCG) - Patos (PB), Brazil.

Department of Odontology, Universidade de Pernambuco (UPE) - Recife (PE), Brazil.

Department of Oral Pathology, Universidade Federal do Rio Grande do Norte (UFRN) - Natal (RN), Brazil.
} 
skeletal dysplasia, and optic gliomas. Also, bone abnormalities - such as bowing deformities, pathological fractures, and pseudoarthrosis of the long bones - may occur in NF-1 due to basic mesodermal dyspla- sia. ${ }^{1,-6}$ We report a case showing five diagnostic criteria, including the presence of café-au-lait spots, neurofibromas, Crowe's sign on both armpits, glioma on the left optic nerve, and paternal family history,
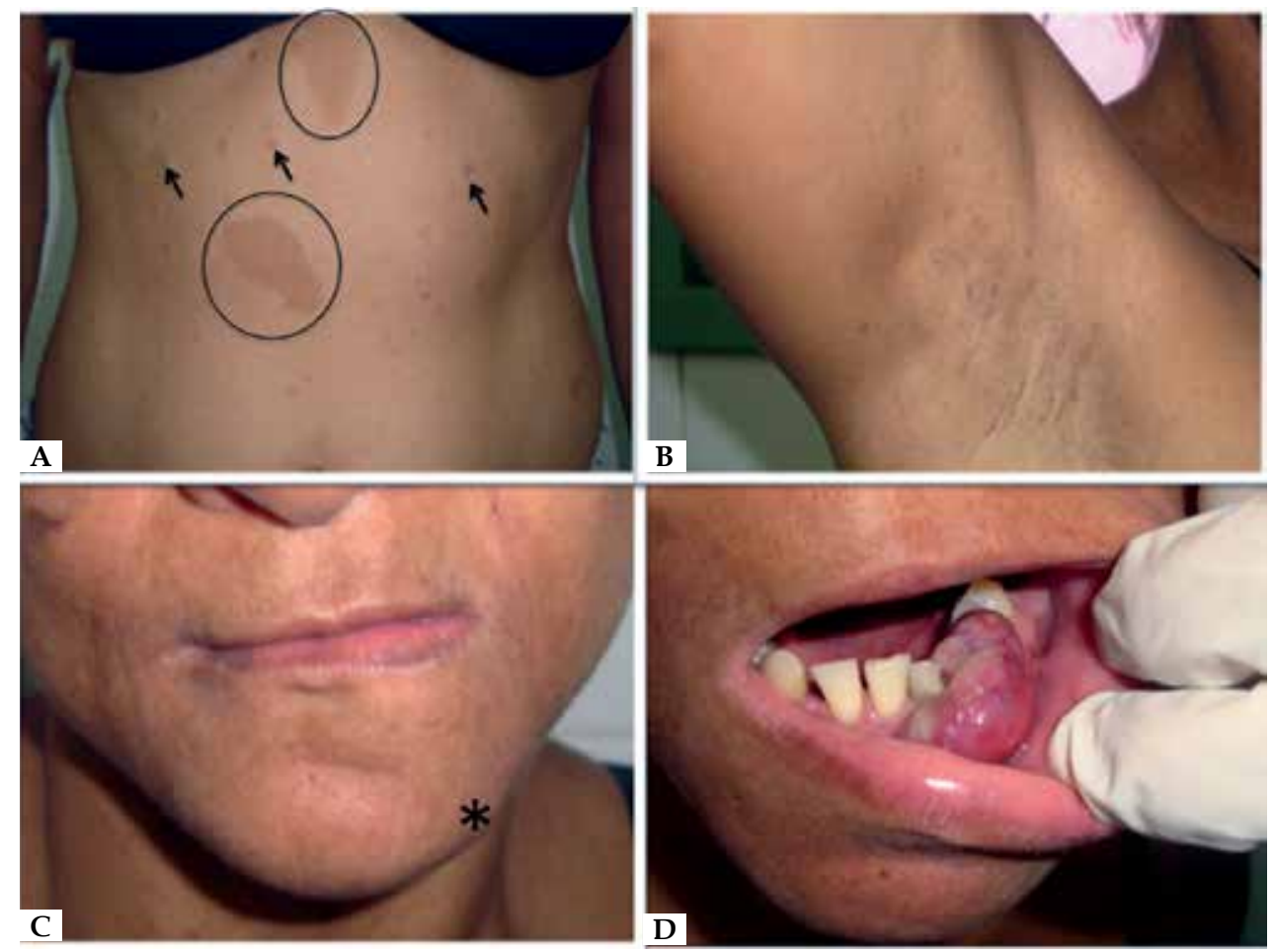

Figure 1: A) Peripheral cutaneous neurofibromas (arrows) and café-au-lait spots (circle) mainly on the trunk and limbs; (B) Crowe's sign. (C) Diffuse swelling on the left side of the face in the anterior mandibular region; (D) Intraoral aspect of PGCG
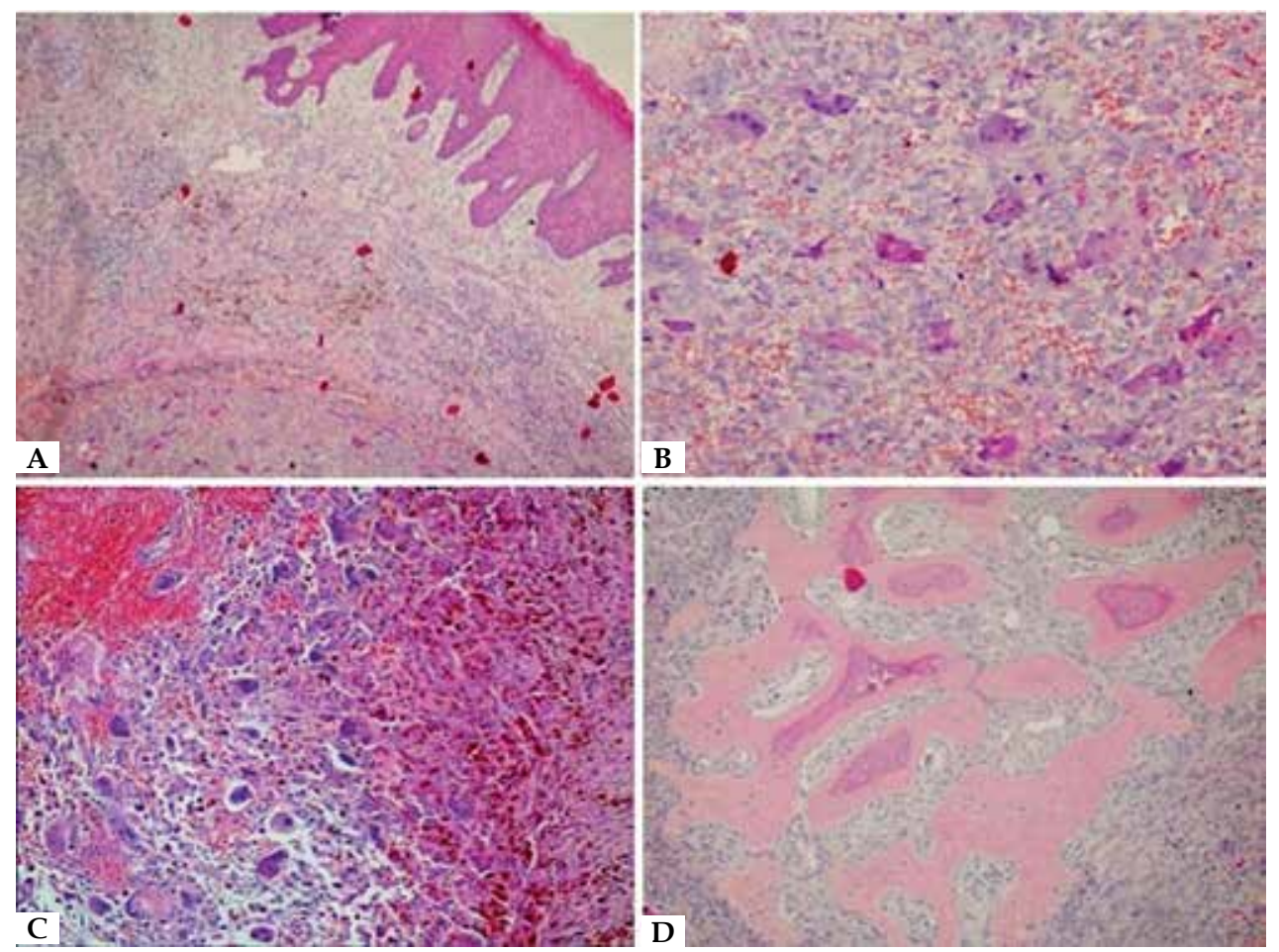

Figure 2: Histopathological examination of specimen showing a highly cellular stroma of connective tissue (A) consisting of a proliferation of spindle-shaped fibroblasts (B), multiple multinucleated giant cells, extravasated red blood cells (C) and trabeculae of reactive bone (D) 

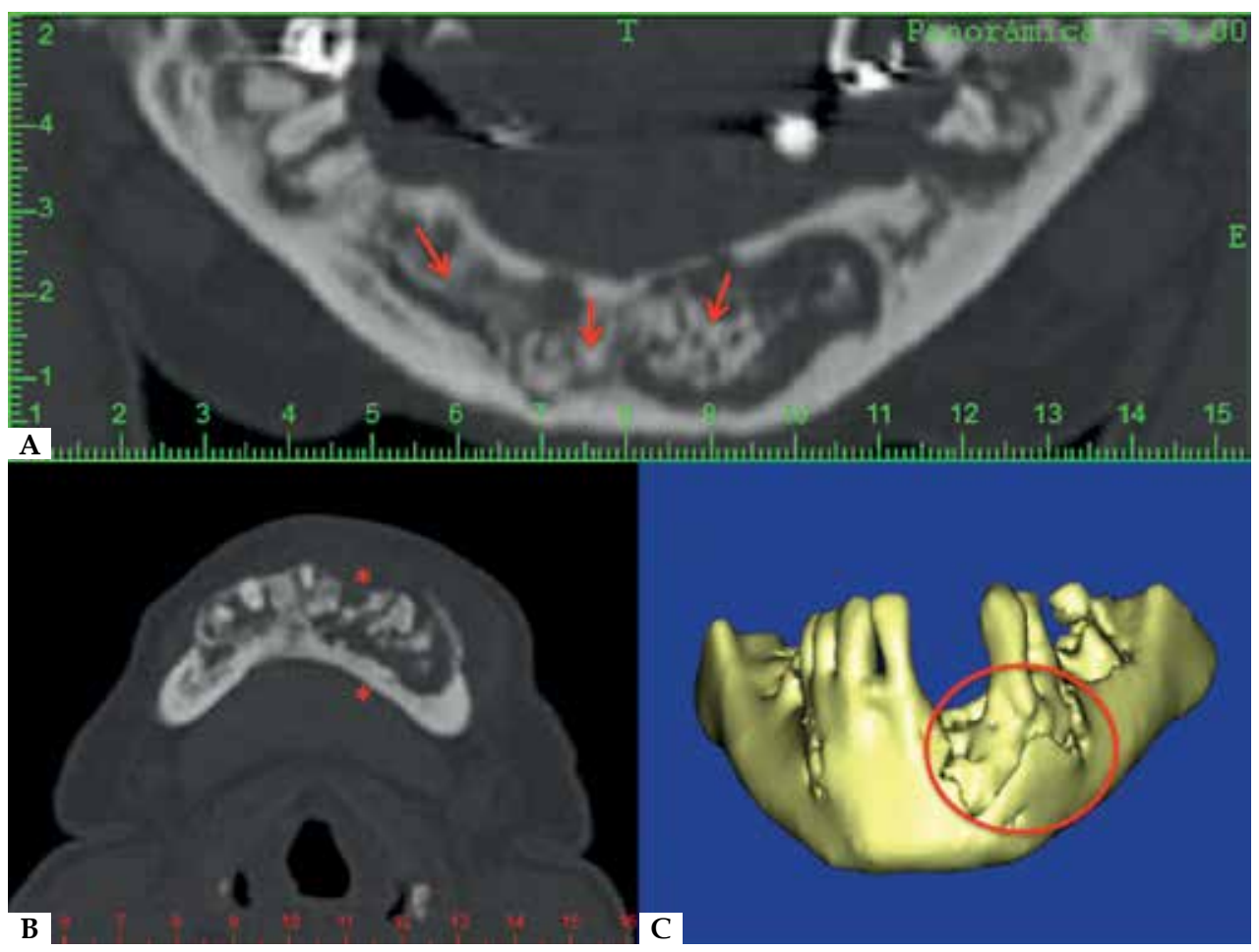

Figure 3: CT scanning of the osseous dysplasias. (A) Panoramic view showing hypodense and hyperdense aspects (arrows); (B) Axial view evidencing expansion of vestibular and lingual cortical bones (asterisk); (C) 3D view suggesting bone destruction (circle)

thus confirming the diagnosis of NF-1.

The NF1 gene was mapped and subsequently cloned and characterized as a protein Ras-GAP. Loss-of-function mutations in the NF1 gene that encodes the protein neurofibromin causes neurofibromatosis type 1 . More than 200 different mutations have been reported so far. In this context, studies suggest a possible activation/involvement of the NF1 gene in the development of giant cell lesions. ${ }^{78}$

Disorders that should be considered in the differential diagnosis of PGCG include pyogenic granuloma, fibrous epulis, peripheral ossifying fibroma, and cavernous hemangioma. The histological study of the resected tissue establishes the definitive diagnosis. ${ }^{9}$ The apparent association between NF-1 and PGCG in the jaw may be a coincidence, or a genetic link, or susceptibility in its development. ${ }^{2}$ More case reports or research is necessary to confirm the association of NF-1 with the predisposition to the emergence of other lesions.

Edwards et al. ${ }^{2}$ believe that the increased incidence of central giant cell granulomas (CGCG) of the jaws in patients with NF-1 most likely represents an inherent susceptibility to intraosseous trauma or bone hemorrhage previously altered by an underlying osseous dysplasia. This qualitatively abnormal bone would be more susceptible to developing CGCG-like lesions in response to still unidentified factors such as excessive mechanical stress or vascular fragility. Our patient had bone dysplasia, which may be related to PGCG. Histological examination of PGCG in this case showed no differences in relation to the features cited in the literature. ${ }^{1,9}$

Florid cemento-osseous dysplasia is a rare benign fibro-osseous condition that characteristically affects the jaw. The cause of this condition is still unknown. Lesions are most commonly seen in middle-aged black women and are usually asymptomatic. In most instances, the disease affects the mandible bilaterally and may or may not show concomitant maxillary involvement. ${ }^{10}$ This case presents similar characteristics as described in the literature, with the peculiarity of a patient with NF-1.

Radiographically, florid cemento-osseous dysplasia is characterized by multiple confluent and nonexpansile radiopacities, often with a circumferential radiolucency. Diagnosis can be made based on radiographic presentation. ${ }^{10}$ Panoramic radiography and CT scanning revealed a mixed appearance of the lesion in our case. Although the lesions extended to the premolar region, we considered periapical cemento-osseous dysplasia as a radiographic differential diagnosis.

It is interesting to mention that some studies reported the presence of CGCG in patients with NF-1. 1,2,7 The gene responsible for NF1 encodes neurofibromin, a protein which acts as a tumor suppressor, the loss of which leads to an increased risk of developing tumors. ${ }^{2}$ This may explain the appearance of the lesions in our patient. Despite the considerable number of patients with NF-1 reported in the literature, to our knowledge, this case is the first to report a patient with NF-1 presenting cemento-osseous dysplasia and PGCG. Dermatologists should consider the possibility of other tumor development in patients with NF-1. In addition, a thorough and multidisciplinary evaluation of these patients is essential. $\square$ 


\section{REFERENCES}

1. Chrcanovic BR, Gomez RS, Freire-Maia B. Neurofibromatosis type 1 associated with bilateral central giant cell granuloma of the mandible. J Craniomaxillofac Surg. 2011;39:538-43.

2. Edwards PC, Fantasia JE, Saini T, Rosenberg TJ, Sachs SA, Ruggiero S. et al. Clinically aggressive central giant cell granulomas in two patients with neurofibromatosis 1. Oral Surg Oral Med Oral Pathol Oral Radiol Endod. 2006;102:765-72.

3. Ruggieri M, Pavone V, Polizzi A, Albanese S, Magro G, Merino M, et al. Unusual form of recurrent giant cell granuloma of the mandible and lower extremities in a patient with neurofibromatosis type 1. Oral Surg Oral Med Oral Pathol Oral Radiol Endod. 1999;87:67-72.

4. Barnes L, Eveson JW, Reichart P, Sidransky D. Pathology and genetics of head and neck tumours. Lyon: IARC Press; 2005.

5. Masocco M, Kodra Y, Vichi M, Conti S, Kanieff M, Pace M, et al. Mortality associated with neurofibromatosis type 1: a study based on Italian death certificates (1995-2006). Orphanet J Rare Dis. 2011;6:11.

6. Duong TA, Sbidian E, Valeyrie-Allanore L, Vialette C, Ferkal S, Hadj-Rabia S, et al. Mortality associated with neurofibromatosis 1 : a cohort study of 1895 patients in 1980-2006 in France. Orphanet J Rare Dis. 2011;6:18

7. Friedrich RE, Mautner VF, Scheuer HA. Loss of heterozygosity in tumor cells of a recurrent mandibular giant cell granuloma in neurofibromatosis Type 1. Anticancer Res. 2007;27:2079-83.

8. Krammer U, Wimmer K, Wiesbauer P, Rasse M, Lang S, Müllner-Eidenböck A, et al. Neurofibromatosis 1: a novel NF1 mutation in an 11-year-old girl with a giant cell granuloma. J Child Neurol. 2003;18:371-3.

9. Chaparro-Avendaño AV, Berini-Aytés L, Gay-Escoda C. Peripheral giant cell granuloma. A report of five cases and review of the literature. Med Oral Patol Oral Cir Bucal. 2005 ; 10:53-7; 48-52.

10. Sarmento DJ, Monteiro BV, de Medeiros AM, da Silveira EJ. Severe florid cementoosseous dysplasia: a case report treated conservatively and literature review. Oral Maxillofac Surg. 2013;17:43-6.
MAILING ADDRESS:

Dmitry José de Santana Sarmento

Avenida Coronel Pedro Targino, s/n

Centro

58233-000 - Araruna - PB

Brazil

E-mail:dmitry_sarmento@hotmail.com

How to cite this article: Sarmento DJS, Carvalho SHG, Araújo Filho JCWP, Carvalho MV, Silveira EJD. Florid cemento-osseous dysplasia and peripheral giant cell granuloma in a patient with neurofibromatosis type 1. An Bras Dermatol. 2017;92(2):249-52. 